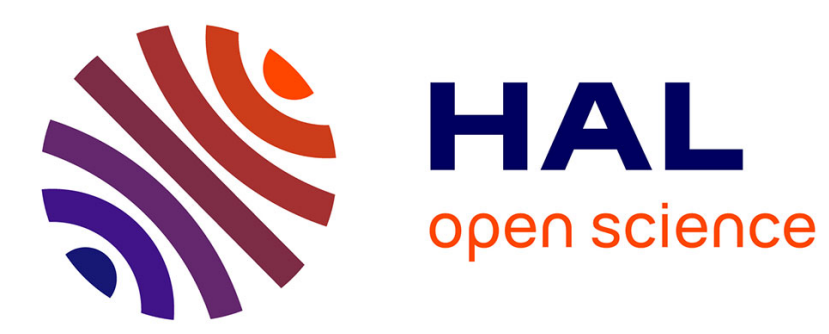

\title{
Climatic effects on radial growth of major tree species on Changbai Mountain
}

Yu, Wang, Zhou, Ding, Fang, Jiang, Dai

\section{To cite this version:}

Yu, Wang, Zhou, Ding, Fang, et al.. Climatic effects on radial growth of major tree species on Changbai Mountain. Annals of Forest Science, 2011, 68 (5), pp.921-933. 10.1007/s13595-011-0098-7 . hal-00930831

\section{HAL Id: hal-00930831 \\ https://hal.science/hal-00930831}

Submitted on 1 Jan 2011

HAL is a multi-disciplinary open access archive for the deposit and dissemination of scientific research documents, whether they are published or not. The documents may come from teaching and research institutions in France or abroad, or from public or private research centers.
L'archive ouverte pluridisciplinaire HAL, est destinée au dépôt et à la diffusion de documents scientifiques de niveau recherche, publiés ou non, émanant des établissements d'enseignement et de recherche français ou étrangers, des laboratoires publics ou privés. 


\title{
Climatic effects on radial growth of major tree species on Changbai Mountain
}

\author{
Dapao Yu • Qingwei Wang • Yue Wang • \\ Wangming Zhou $\cdot$ Hong Ding $\cdot$ Xiangmin Fang • \\ Shenwei Jiang • Limin Dai
}

Received: 29 November 2010 / Accepted: 14 April 2011 /Published online: 13 July 2011

(C) INRA and Springer Science+Business Media B.V. 2011

\begin{abstract}
- Introduction Information on spatial variability in tree radial growth is essential for improving predictions of forest ecosystem responses to climate change. To date, researchers have designed models to simulate the potential distribution area of major forest types under different climate change scenarios in Northeast China, but little is known about the spatial variability of tree growth in response to climate.

- Materials and methods We used a dendroecological technique to examine the climate-growth relationship of six dominant tree species on seven sites varying in altitude on Changbai Mountain in Northeast China, to explore whether the spatial variability of tree growth is an indicator of regional climatic forces, and whether simulation results generated by models can accurately reflect this in tree radial growth.

- Results Fifteen site-specific species can be distinguished species at or near their upper limit distribution from those at the lower distributions. Species differences were more important than altitude differences in influencing species' site-specific radial growth. Precipitation, temperature, and soil moisture together constitute the major factors limiting tree radial growth

- Conclusion We found the distribution area of dominant tree species on Changbai Mountain will shift upward;

Handling Editor: Guofan Shao

D. Yu $(\bowtie) \cdot$ Q. Wang $\cdot$ Y. Wang $\cdot$ W. Zhou $\cdot$ H. Ding $\cdot$ X. Fang $\cdot$

S. Jiang $\cdot$ L. Dai

Key Laboratory of Forest and Soil Ecology,

Institute of Applied Ecology, Chinese Academy of Sciences,

72 Wenhua Road,

Shenyang City, Liaoning Province, China 110016

e-mail: yudp2003@iae.ac.cn

L. Dai

e-mail: 1mdai@iae.ac.cn
\end{abstract}

growth of Korean pine will not decline at its lower limit of distribution and will not eventually even disappear from forest communities in those areas.

Keywords Climate response - Tree ring .

Dendrochronology Changbai Mountain · Northeast China

\section{Introduction}

Climate change and its effects on forest ecosystems have generated wide public concern. Better predictions of how forest ecosystems will respond to climate change require a precise understanding of species- and site-specific responses to climate (Cook et al. 2001). In hilly and mountainous areas, for example, elevational differences exert a strong influence on microclimate - especially air temperature, humidity, and soil moisture - and as a consequence on climate-tree growth relationships (Liang et al. 2006, 2010). On the other hand, Graumlich (1993) reported that species differences were more important than site differences in the forests of Wisconsin and upper Michigan, where elevational differences are not as distinct. These results illustrate the complexity of species- and sitedependent growth response to climate, and the results also suggest that predicting the impacts of global change on mountainous forests requires a more complete accounting of tree growth-climate-site interactions. (Andreassen et al. 2006; Liang et al. 2010).

To date, researchers in Northeast China have designed models to simulate the dynamics of forest composition and structure, and the potential distribution area of major forest types under different climate change scenarios (e.g., Zhao et al. 1998; Xu and Yan 2001; Shao et al. 2003; He et al. 2005). These studies have suggested that distributions of 
the dominant conifer tree species in the region under climate warming will be manifest via northward geographic and upward altitudinal shifts. Most of the simulation results in the region have yielded consistent results. If these results are realistic, the shifts should be reflected in variation in tree composition and forest structure, which would first be reflected in tree radial growth. Distribution of a given tree species should be extended geographically at its upper limit and recede from its lower limit. Forest composition and structure will change, as dominance of tree species in a given forest type will be magnified or reduced depending on their response to climate change. Such responses have contributed to the basic assumptions and preconditions of most models (Yan et al. 2000; Hao et al. 2001; He et al. 2005).

Dendrochronological studies at broad spatial and temporal scales could provide useful information on the spatiotemporal variation of tree growth (Tardif et al. 2003). These studies are also essential to validate climate model simulations in climate-sensitive regions such as the high-latitude Northeast China. Presently, most of the treering research in China centers on the reconstruction of past climatic series (e.g., Zhu et al. 2009; Liu et al. 2009), which requires relatively older trees and those more sensitive to climatic variations. Compared to forests in West China, trees in Northeast China have a younger age and lower sensitivity to climatic factors, which has resulted in the relative lack of dendrochronological studies in the region.

Changbai Mountain, the core area of this vegetation zone, is covered with a large area of undisturbed temperate oldgrowth forest (Shao and Zhao 1998). It is characterized by a vertical zonation of three forest ecosystems along the altitudinal gradient. They also represent the major forest types in Northeast China along the latitudinal gradient. This makes Changbai Mountain an ideal setting to examine growthclimate interactions. Previous tree-ring studies on Changbai Mountain have focused primarily on single forest sites (Shao and Wu 1997; Yu et al. 2007) and single tree species (Yu et al. 2005, 2006; Zhang et al. 2007; Zhu et al. 2009).

Changbai Mountain is characterized by abundant precipitation and low temperature, as well as an incremental increase in precipitation and decrease in temperature along the elevational gradient. Dendrochronological studies have suggested that precipitation is a critical factor limiting radial growth on Changbai Mountain and that trees growing at the upper limit of their distribution range are more affected by precipitation than by temperature (Yu et al. 2007). This runs counter to the traditional view that temperature, particularly in the in growing season, is the factor limiting radial growth of trees in cool regions (e.g., Splechtna et al. 2000; Frank and Esper 2005). Due to different data processing methods, results of some studies could not be adequately compared. At present, little is known about the spatial variability of tree growth over the entire altitudinal gradient in response to climate on Changbai Mountain. It is still an open question as to whether the spatial variability of tree growth is an indicator of regional climatic forces, and whether simulation results generated by models can accurately reflect this in tree radial growth.

This study analyzed a tree-ring network based on data for six dominant tree species at seven elevations along an altitudinal gradient on Changbai Mountain. The objectives were to: (1) explore the spatial patterns of tree growth along an altitudinal gradient, (2) examine site-specific variation in tree species growth and its response to climate, and (3) detect and verify dominant tree species distribution trends under future climate scenarios.

\section{Materials and methods}

\subsection{Study area}

The study area is located on the northern slope of the Changbai Mountain Natural Reserve in Northeast China $\left(41^{\circ} 31^{\prime}-42^{\circ} 28^{\prime} \mathrm{N}, 127^{\circ} 9^{\prime}-128^{\circ} 55^{\prime} \mathrm{E}\right.$ ) (Fig. 1). The climate of the study area is characterized by cold, windy winters and wet summers. Average annual precipitation increases with elevation, from approximately $680 \mathrm{~mm}$ at 740 masl to $1,020 \mathrm{~mm}$ at 2,000 masl. About $80 \%$ of the total annual precipitation occurs between June and September (Fig. 2). The average annual temperature decreases with elevation from about $2.8^{\circ} \mathrm{C}$ at 700 masl to $-3.8^{\circ} \mathrm{C}$ at 2,000 masl.

The altitudinal vegetation zonation within the study area has been well documented (e.g., Wang et al. 1980). Four altitudinal vegetation zones have been recognized, including broad-leaved and Korean pine mixed forest (BP) extending from approximately $740 \mathrm{~m}$ to $1,100 \mathrm{masl}$; spruce-fir forest (SF) - also known as dark coniferous forest-from 1,100 to 1,800 masl; Ermans birch forest (EB), which forms the upper limit of forest distribution, from 1,800 to $2,000 \mathrm{masl}$; and alpine tundra above 2,000 masl. The vegetation found between 1,050 and $1,250 \mathrm{~m}$ is an ecotone (BS) encompassing the transition from $\mathrm{BP}$ to $\mathrm{SF}$, and that between 1,760 and $1,810 \mathrm{~m}$ is an ecotone (SE) from SF to EB (Yu et al. 2004).

\subsection{Tree species and sampling sites}

Along the altitudinal gradient of the Changbai Mountain Natural Reserve, the lowest vegetation zone (BP) is dominated by Korean pine (Pinus koraiensis Sieb. et Zucc.) - the only conifer tree species in this zone-and Manchurian Ash (Fraxinus mandshurica Rupr.). Korean pine is actually distributed from 740 to $1,450 \mathrm{~m}$; this includes two forest types (BP and SF) and one ecotone 
Fig. 1 Location of the Changbai Mountain Natural Reserve in Northeast China, its forest vegetation zones and study sample sites

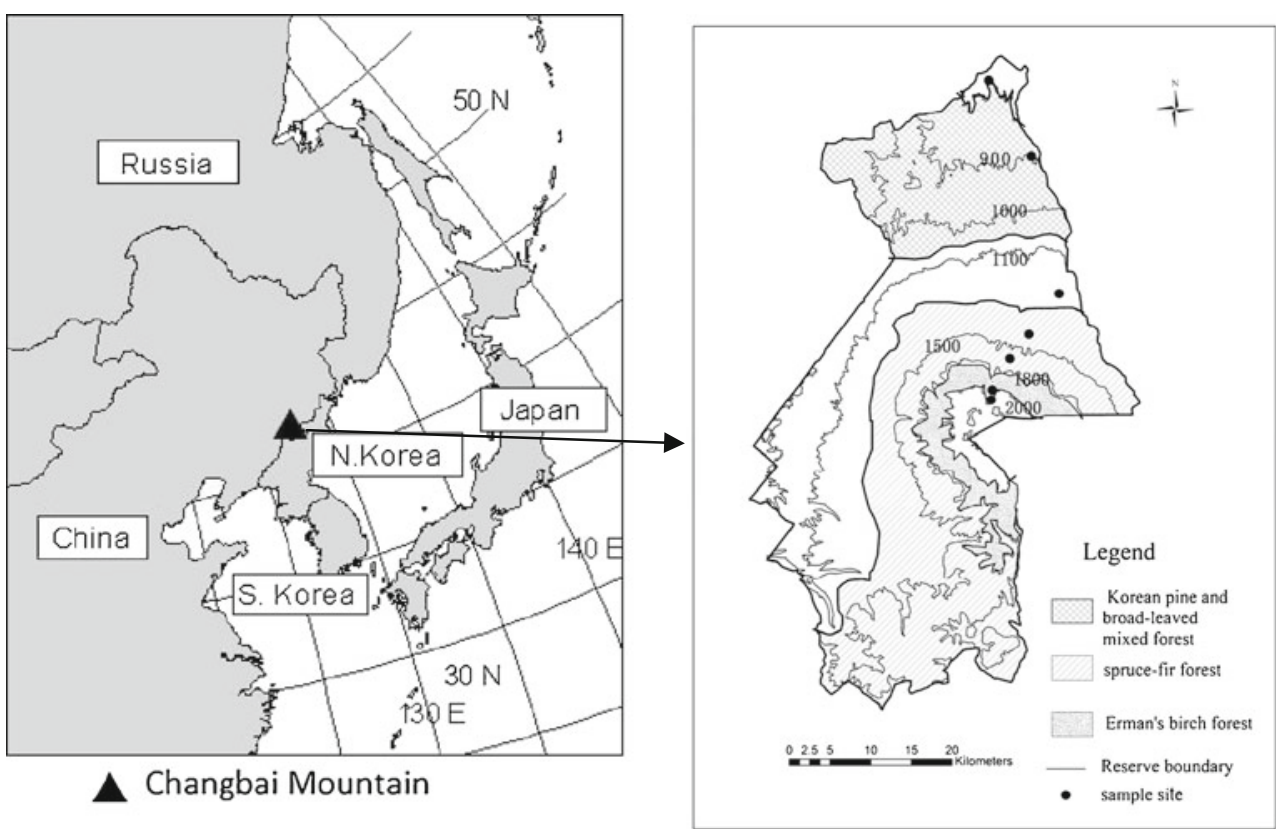

(BS). Manchurian Ash is found mainly in BP from 740 to $1,050 \mathrm{~m}$. In SF, the dominant tree species are spruce (Picea jezoensis Carr. var. komarovii (V.Vassil.) Cheng and $\mathrm{Fu}$ ) and fir (Abies nephrolepis (Trautv.) Maxim). Spruce and fir are distributed from 900 to $1,800 \mathrm{~m}$, with the latter more prevalent at lower elevations of SF $(1,250-1,470 \mathrm{~m})$, and spruce exceeding fir at higher elevations of SF $(1,480$ $1,750 \mathrm{~m})$. The vast majority of trees in EB are Erman's birch (Betula ermanii Cham.) along with few larches (Larix olgensis A. Henry). While larch is not the dominant tree species in any of the three forest types, it is widely distributed on the Mountain, in some places forming a single community in which it dominates. Given their overall importance across the altitudinal gradient of forested zones on Changbai Mountain, these six tree species were selected for sampling in this study.

Taking into account tree species and their distribution on Changbai Mountain, seven samples sites, extending to

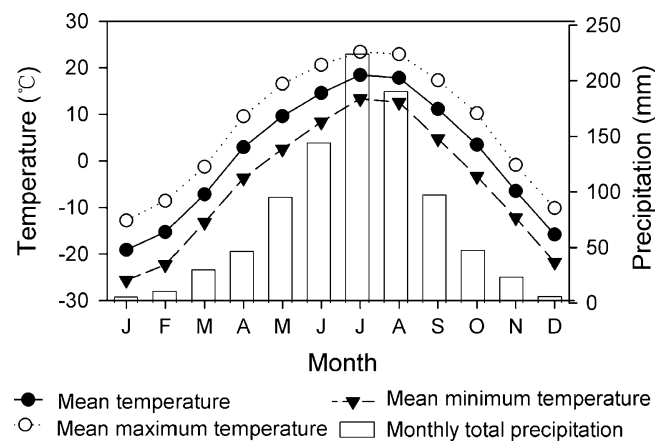

Fig. 2 Monthly total precipitation and mean maximum temperature, mean temperature, and mean minimum temperature at Changbai Mountain. Climate data from 1900 to 2000 are derived from grid data $\left(127-129^{\circ} \mathrm{N}, 41-43^{\circ} \mathrm{E}\right)$ approximately $1,300 \mathrm{~m}$ in elevation, were selected for this study. For each site, three $20 \times 90 \mathrm{~m}$ plots were established and approximately 20 relatively large canopy trees were sampled per site. If the number of stems available for dendrochronology analysis was less than 20 , then trees on the edge of the plots were sampled.

\subsection{Chronology development}

A total of 15 site-specific species on Changbai Mountain between 750 and 2,000 m were sampled (Table 2). "Sitespecific" refers to the fact that the same species may exhibit different growth characteristics depending on the site on which it is found. Thus the radial growth of a given species will in part be a function of the specific site (altitude and other factors) at/on which it is situated. For each site, at least 20 dominant trees were selected, and two cores were taken per tree at breast height (approximately $1.3 \mathrm{~m}$ ). Except for Manchurian Ash (sampled by Zhang et al. (2007)), trees on 14 of the 15 sites were sampled by us in 2003 and 2007, and results for eight sites were subsequently published (Yu et al. 2005, 2006, 2007). Additionally, in order to increase the amount and length of Korean pine, fir, and larch cores, 46 stems were resampled for this study in 2009.

In order to unify the data processing techniques, ring width series were redeveloped using standard dendrochronological techniques (Fritts 1976). Age- and size-related variation in tree-ring widths was removed by fitting a negative exponential curve or a straight line with negative slope (Cook 1985). In few cases when anomalous growth trends occurred, a cubic spine with a $50 \%$ frequency response cutoff equal to $67 \%$ of the series length was 
utilized. The ring width of each core was divided by the fitted line value to produce a standardized tree-ring series. These individual dimensionless index series were then averaged using a bi-weight robust mean to develop mean standardized (STD) chronologies (Fritts 1976). Thus, a total of 15 standard ring width chronologies were developed (Fig. 1, Table 1).

\subsection{Multivariate analysis}

All chronologies had an expressed population signal (EPS) $>0.85$ for the period 1900-2000 (Table 1), which was therefore selected for the multivariate analysis. Principal component (PC) analysis, based on a correlation matrix of the 15 STD chronologies over a common period of 19022000 , was used to identify dominant spatial patterns in annual radial growth and reveal the climatic signals driving these patterns. Only those components that explained at least $5 \%$ of the variance in the original variables was retained, a criterion used in similar dendrochronological studies (Peterson and Peterson 2001).

\subsection{Climate-growth relationships}

Climatic variables utilized in this study included minimum, mean, and maximum monthly temperature; total monthly precipitation; and the Palmer Drought Severity Index (PDSI), which can be used to determine the beginning, end, and severity of a drought period. The
PSDI extends over a 14-month window from September - the end of the previous year's growing season at the tree line $(2,000 \mathrm{masl})$ - through October - the end of the current year growing season near the lower boundary of Changbai Mountain vegetation zones at 750 masl. Climate data were obtained from the high-resolution gridded climate dataset CRUTS2.1 (Mitchell and Jones 2005). Gridpoints between $127-129^{\circ} \mathrm{N}, 41-43^{\circ} \mathrm{E}$ were used contributing climate data (temperature and precipitation) from 1900 to 2000. For this study, PDSI data (Dai et al. 2004) for 1910-2000 were obtained from the gridpoint between 127 and $130^{\circ} \mathrm{N}, 40-42.5^{\circ} \mathrm{E}$.

Correlations between tree ring chronologies, principal component scores, and climatic variables were examined via Pearson correlation (Briffa and Jones 1990). These analyses were performed with the program PRECON [version 5.17B]. Given that the climatic variables may have cumulative or longterm effects, the relationship between annual periods of the climate data (October in previous year to September in current year) and radial growth were also examined using Pearson correlation analysis.

\section{Results}

\subsection{Chronology characteristics}

Fifteen STD were developed with lengths ranging from 142 to 287 years and a mean age (at coring height) of from 78 to

Table 1 Sites,-species and descriptive statistics for the 15 standard tree-ring chronologies along an altitudinal gradient on Changbai Mountain

\begin{tabular}{|c|c|c|c|c|c|c|c|c|c|c|c|c|}
\hline $\begin{array}{l}\text { Site } \\
\text { no. }\end{array}$ & $\begin{array}{l}\text { Tree } \\
\text { species }\end{array}$ & Site--species & $\begin{array}{l}\text { Elev. } \\
\text { (m asl) }\end{array}$ & Core/stem & $\begin{array}{l}\text { Mean } \\
\text { age }\end{array}$ & $\begin{array}{l}\text { Mean width } \\
(\mathrm{mm})(\mathrm{SD})\end{array}$ & MS & SD & rbar & $\begin{array}{l}\mathrm{EPS}>0.85 \\
\text { since }\end{array}$ & $\mathrm{PC} 1$ & EPS \\
\hline 1 & PNK & PNK1 & 750 & $47 / 30$ & 133 & $1.98(0.67)$ & 0.165 & 0.179 & 0.476 & 1802 & 47.13 & 0.93 \\
\hline 1 & FM & FM1 & 750 & $40 / 20$ & - & $0.93(0.37)$ & 0.105 & 0.202 & 0.582 & 1763 & 38.03 & 0.92 \\
\hline 2 & $\mathrm{AN}$ & AN2 & 900 & $42 / 28$ & 96.1 & $1.79(0.58)$ & 0.13 & 0.174 & 0.423 & 1901 & 30.46 & 0.94 \\
\hline 2 & PCK & PCK2 & 900 & $32 / 18$ & 144 & $1.62(0.66)$ & 0.133 & 0.178 & 0.577 & 1867 & 38.32 & 0.89 \\
\hline 3 & PNK & PNK3 & 1,200 & $37 / 19$ & 159 & $1.57(0.38)$ & 0.141 & 0.186 & 0.553 & 1787 & 35.47 & 0.94 \\
\hline 3 & PCK & PCK3 & 1,200 & $42 / 23$ & 91 & $1.39(0.61)$ & 0.141 & 0.335 & 0.548 & 1900 & 44.29 & 0.94 \\
\hline 3 & LO & LO3 & 1,200 & $50 / 28$ & 156 & $1.09(0.26)$ & 0.164 & 0.228 & 0.581 & 1887 & 40.16 & 0.93 \\
\hline 4 & PNK & PNK4 & 1,400 & $40 / 21$ & 147 & $1.42(0.40)$ & 0.119 & 0.166 & 0.607 & 1792 & 42.26 & 0.91 \\
\hline 4 & AN & AN4 & 1,400 & $32 / 19$ & 98 & $1.43(0.38)$ & 0.136 & 0.131 & 0.49 & 1896 & 31.65 & 0.93 \\
\hline 4 & PCK & PCK4 & 1,400 & $42 / 21$ & 161 & $1.16(0.48)$ & 0.146 & 0.176 & 0.569 & 1865 & 46.28 & 0.94 \\
\hline 5 & PCK & PCK5 & 1,600 & $53 / 30$ & 195 & $0.98(0.40)$ & 0.162 & 0.172 & 0.652 & 1823 & 38.82 & 0.97 \\
\hline 6 & $\mathrm{AN}$ & AN5 & 1,800 & $29 / 18$ & 88 & $1.37(0.51)$ & 0.146 & 0.228 & 0.613 & 1901 & 34.89 & 0.93 \\
\hline 6 & PCK & PCK6 & 1,800 & $35 / 17$ & 156 & $1.07(0.43)$ & 0.17 & 0.209 & 0.654 & 1813 & 42.16 & 0.89 \\
\hline 7 & LO & LO7 & 2,000 & $30 / 14$ & 171 & $0.69(0.25)$ & 0.232 & 0.282 & 0.491 & 1826 & 52.32 & 0.89 \\
\hline 7 & $\mathrm{BM}$ & BM7 & 2,000 & $58 / 30$ & 167 & $0.51(0.23)$ & 0.231 & 0.238 & 0.356 & 1806 & 35.7 & 0.92 \\
\hline
\end{tabular}

PNK, Pinus koraiensis; FM, Fraximus mandshurica; AN, Abies nephrolepis; PCK, Picea koraiensis; LO, Larix olgensis; BM, Betula ermanii

Elev elevation, $M S$ mean sensitivity, $S D$ standard deviation, rbar mean interseries correlation, eps expressed population signal, $P C 1$ first principal component 
195 years (Table 1). The mean raw ring width ranged from 1.978 to $0.508 \mathrm{~mm}$, and in general decreased significantly with increasing altitude $(p<0.0001$; Fig. 3a). The highest value appeared in Korean pine at $750 \mathrm{~m}$ elevation and the smallest value was for Erman's birch at 2,000 m. There were no significant differences in annual ring width among the evergreen conifer tree species-Korean pine, fir, and spruces - at a given altitude. They were, however, clearly larger than those of deciduous tree species, i.e., Manchurian ash and larch, at the same altitude (Table 1).

The mean sensitivity (MS) and standard deviation (SD), which are used to assess the statistical-dendroclimatological quality of tree-ring chronologies, may also be found in Table 1. The MS and SD ranged from 0.105 to 0.232 and from 0.131 to 0.335 , respectively, with the highest values appearing for larch and Erman's birch near the tree line $(2,000 \mathrm{masl})$ and the lowest values for Manchurian ash at 750 masl. The MS for all chronologies increased with increasing elevation $(P<0.0001$; Fig. $3 b)$, with the exception of the three Korean pine chronologies which displayed a downward trend along the altitudinal gradient $(P<0.0001$; Fig. $3 \mathrm{c})$. The values of mean interseries correlation (rbar) are relatively high $(0.356-$ $0.654)$ suggesting that they recorded sufficient environmental signals. Values for rbar also displayed an increasing trend along the altitudinal gradient, with the exception of larch and Erman's birch growing at the tree line (Fig. 3d). Common interval analysis also revealed the 15 chronologies have a high EPS $(0.87-0.97)$ and a relatively high variance according to loadings on the first principal component (30.46-52.32\%).

\subsection{Multivariate analysis}

The first six PCs of the 15 chronologies each explained more than $5 \%$ of the variance individually $(37.4 \%, 13.5 \%$, $10.4 \%, 6.9 \%, 6.3 \%$, and $5.6 \%$ ) and cumulatively accounted for $80.1 \%$ of the total variance. These six components were then used in the following analysis to examine spatial growth patterns and to identify their possible responses to environmental factors.

Loadings for the first and second components (PC1 and PC2) can be used to separate all sites into four major groups (Fig. 4), which in turn may be further divided on the basis of whether they are comprised of species growing at or near their upper or lower altitudinal limits, respectively. Three of the four groups contain species near their upper altitudinal limit of growth. One of these is comprised of species growing at the tree line on Changbai Mountain, including Erman's birch and Larch; while the other two groups are made up of spruce and Korean pine, respectively, at their upper altitudinal limits. The remaining nine site-specific species at their lower altitudinal limits comprise the fourth group.

\subsection{Climate-growth relationships for individual tree-ring chronologies}

The ring width chronologies revealed complex relationships between temperature, precipitation, and tree growth on Changbai Mountain (Fig. 5). Precipitation during the growing season was positively correlated with tree growth for species measured at all sites, which may indicate that
Fig. 3 Main parameters of ring width standard chronologies plotted as functions of elevation: a ring width (original measure), b mean sensitivity (MS) - all cores except Korean pine, $\mathbf{c}$ Mean sensitivity (MS) for Korean pine, and $\mathbf{d}$ Mean interseries correlation (rbar) of all cores (generally two cores from each tree)

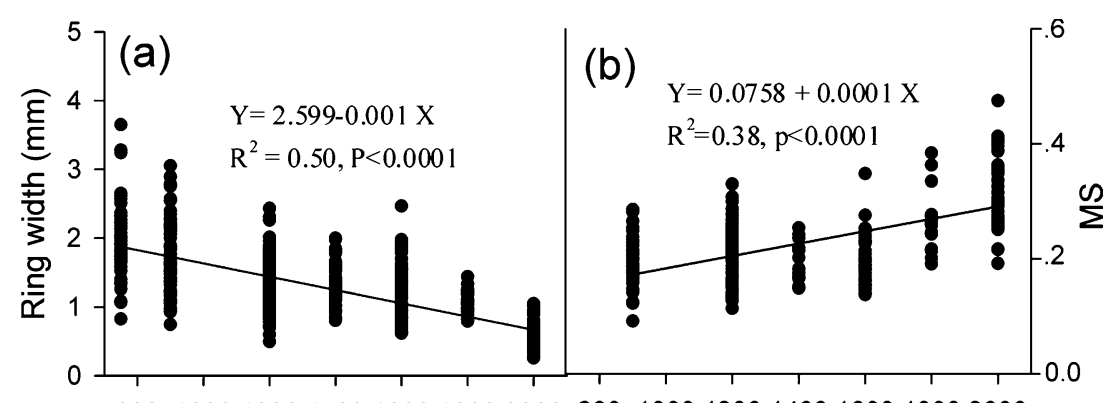

800100012001400160018002000800100012001400160018002000

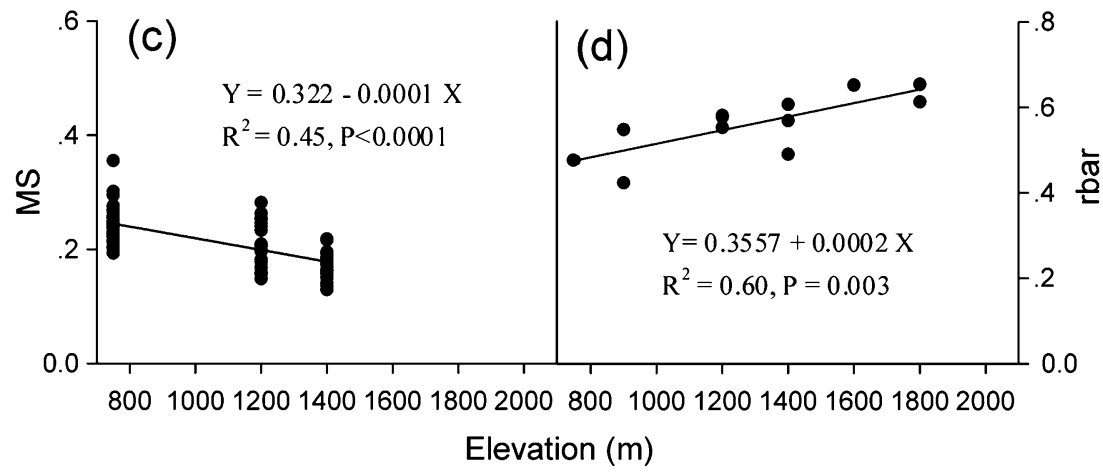




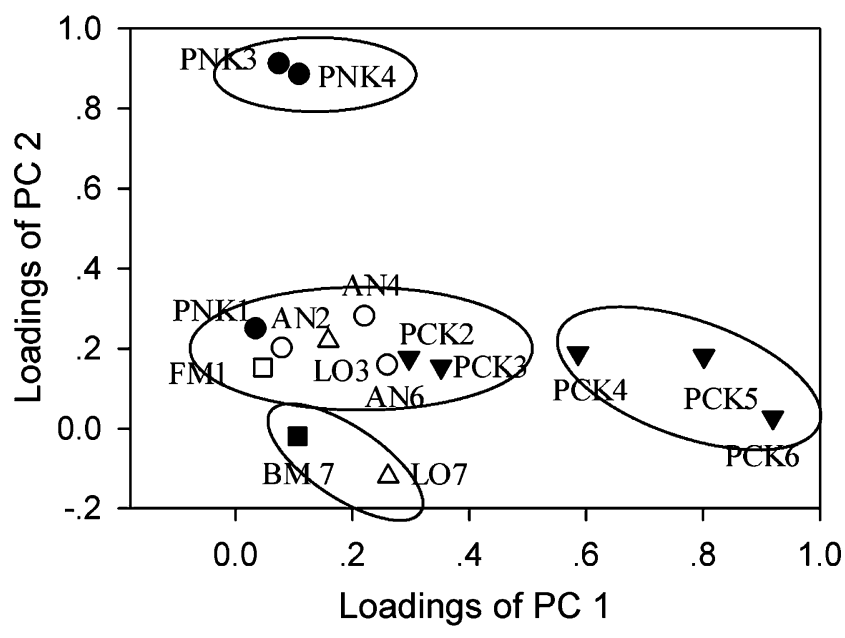

Fig. 4 Individual tree-ring standard chronologies plotted according to their loadings in space by principal component axes

water stress is a common phenomenon on Changbai Mountain. Additionally, spruce at the higher elevations (PCK4, PCK5, PCK6; Fig. 5j, k, n) and Erman's birch at tree line (BM7; Fig. 5n) also displayed positive correlations with precipitation during winter.

At the same time, complex relationships were found with respect to the effects of temperature on tree radial growth. Korean pine growth at all three sites had a significant positive correlation with previous September (end of growing season) temperature, and current March and April temperatures (late spring); while those growing at higher altitudes and near the upper limit of growth showed significant positive correlations with current growing season (July and August) minimum and mean temperatures $(p<0.05$; Fig. 5a-c). With respect to fir, current growing season (August and September) mean temperatures also had positive effects on tree radial growth at low altitude $(p<$ 0.05; AN2) (Fig. 5d), but June and July minimum temperature had negative effects at two high altitude sites $(p<0.05$, AN4, AN5; Fig. 5e, f). Spruces at three low altitude sites were negatively correlated with temperature during the growing season (Fig. $5 \mathrm{~g}-\mathrm{i}$ ), while those at the upper limit of growth were positively correlated with temperature (Fig. 5k).

At the tree line, larch growth displayed significant positive correlations with May maximum temperature ( $p=$ 0.011; Fig. 5m), while Erman's birch was significantly positively correlated with previous October $(p=0.05)$ and current-year March minimum temperatures $(p=0.023$; Fig. 5n). With respect to Manchurian Ash, significant correlations were found with minimum temperature in the previous September $(p=0.009)$ and October $(p=0.018)$, as well as current-year February $(p=0.048)$, June $(p=0.011)$, August ( $p=0.05)$, and September ( $p=0.030$; Fig. 5o).

Taking the combined effects of precipitation and temperature into account, the relationships between each chronology and monthly mean PDSI were analyzed (Fig. 6). Korean pine radial growth at all three sites was significantly correlated with July PDSI ( $p<0.05$; Fig. 6a). For spruce at the lowest site (PCK2) and the upper two sites (PCK5 and PCK6), significant correlations were found with PDSI at the end of the growing season in the previous year (the former for September and October, the latter two for September, $p<0.05$ ), while the upper two sites were also significant correlated with the current growing season (July and September, $p<0.05$; Fig. 6b). For larch at lower site, significant correlations were found with PDSIs for the previous September $(p=0.031)$ and current-year March $(p=$ 0.042 ) and April ( $p=0.039$; Fig. 6d). For larch growing at the tree line, no significant effects of PDSI on radial growth were found; but for Erman's birch, significant correlations were found with PDSI for current May $(p=0.05)$ and June $(p=0.031$; Fig. 6e). No significant correlations of monthly PDSI with Manchurian ash or fir were found on any of the one or three sites, respectively, on which they occurred. Thus, on an overall basis, in relating tree chronologies to PSDI, while there were no obvious differences among sites (altitudes), there were significant differences among tree species.

\subsection{Regional variation in radial growth patterns}

All of the 15 site-specific chronologies had a positive loading on PC1, most likely indicating that these sites were affected in a similar way by the regional climate (Fig. 4). For PC1, a large loading appeared for spruce at higher altitudes, while for PC2 it appeared for Korean pine at high altitudes, and the only two negative loadings occurred for the upper tree line site. For PC3 and PC4, the largest loadings were found for fir and spruce at low altitudes, respectively; while for PC5 and PC6, they occurred for larch and Erman's birch at the tree line, respectively, suggesting that the latter respond differently to regional climate than do other species at that altitude.

PC1 score time series exhibited contrasting responses to monthly precipitation and temperature in winter and spring (Fig. 7a). A significant positive correlation was found with precipitation in the previous November $(p<0.01)$, while a significant negative correlation surfaced with current March temperature $(p<0.05$; Fig. 7a).

PC2 displayed a different response to climate variables, showing significant positive correlations with temperature in late growing season (September and October) of the previous year, previous-year March mean temperature and mean maximum temperature $(P<0.05)$, and current-year August minimum temperature $(p<0.05)$ and precipitation $(p<0.05$; Fig. 7b).

PC3 displayed high negative correlations with minimum temperature for the period from February to August of the 
Fig. 5 Correlations between each tree-ring standard chronology and mean climatic variables derived from grid data $(1902-$ 2000) from September of previous year to October of the current year. Dashed lines indicate significant correlations at $p$ $<0.05$ and $p<0.01$, respectively

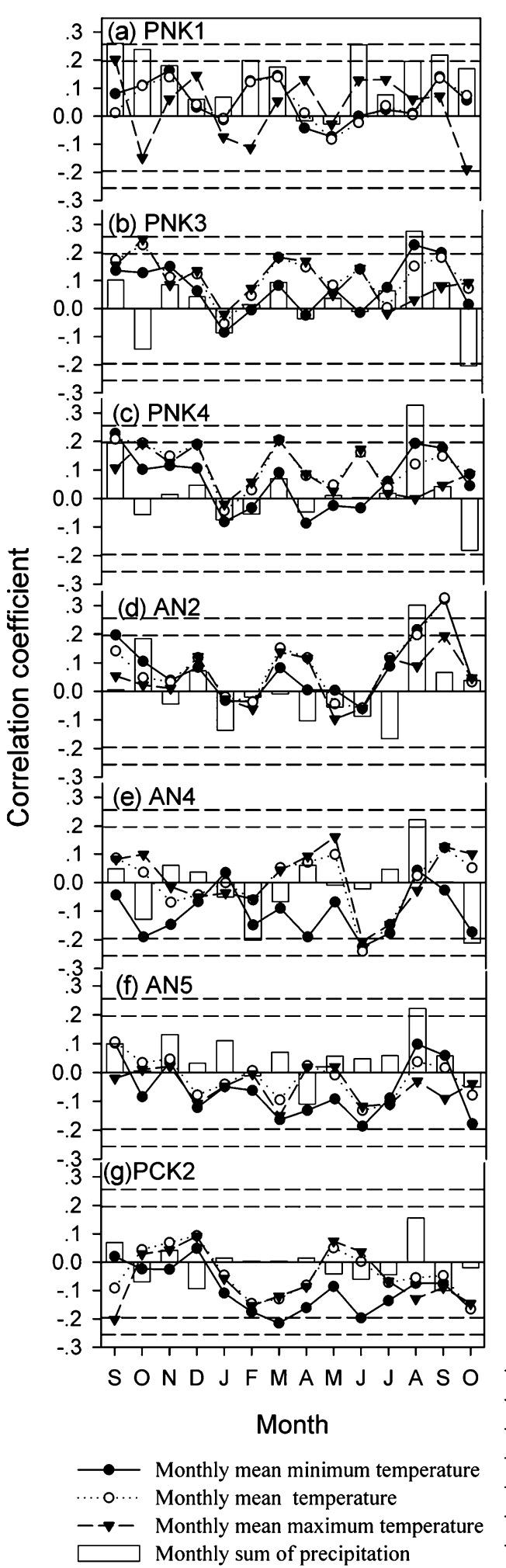

current year; however, no significant correlations with precipitation were found (Fig. 7c).

For PC4, significant correlations were found with precipitation for the previous October and current July

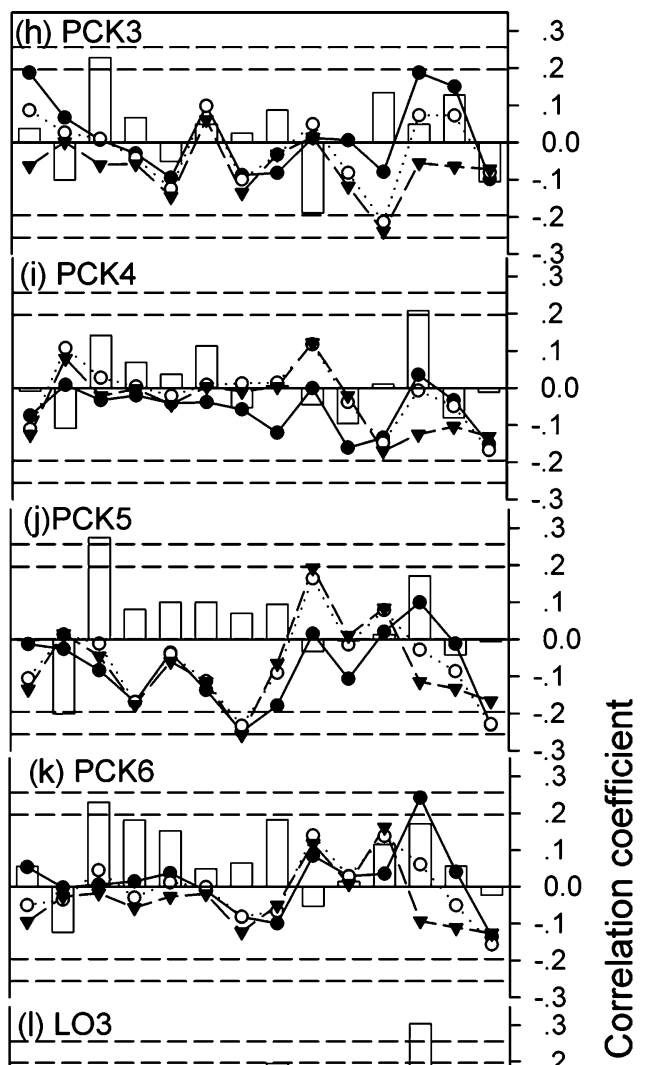

$S O N D J F M A M J J A S O$

Month 


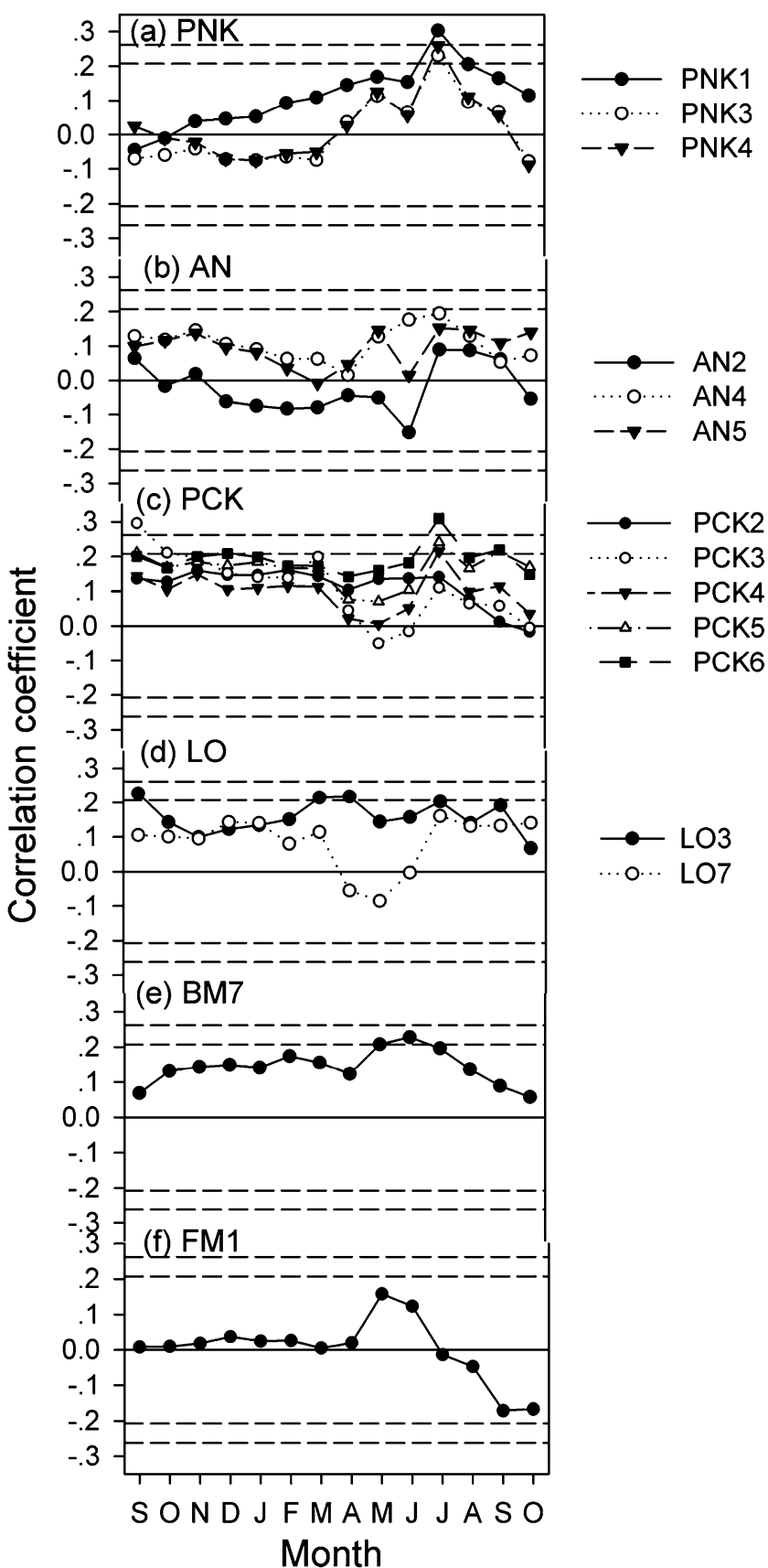

Fig. 6 Correlations between each tree-ring standard chronology and mean PDSI derived from grid data (1911-2000) from September of previous year to October of the current year. Dashed lines indicate significant correlations at $p<0.05$ and $p<0.01$, respectively

tions were found with minimum temperature in the previous September $(r=0.208, p<0.05)$ and current June $(r=0.220, p<0.05)$, and with precipitation in the previous September $(r=0.203, p<0.05$; Fig. 7e).

Finally, for PC6, significant correlations were displayed with minimum temperature in the previous December $(r=$ $0.241, p<0.05)$ and current July $(r=0.222, p<0.05)$, and with precipitation in current July $(r=0.277, p<0.01$; Fig. $7 \mathrm{f})$.
As evidenced by the correlations of PCs with annual temperature in Fig. 8b, the effects of temperature on tree radial growth may be divided in a straightforward manner into two basic categories: positive (including PC2, PC5, and PC6) and negative (PC1 and PC3; Fig. 8b). With respect to the effects of precipitation, a significant positive correlation was found only in PC6; however, the significant correlation of PC1 and PDSI indicated that drought was still an important limiting factor at that site. Except for PC4 (which explained $6.9 \%$ of the total variance), the other five PCs (explaining $73.2 \%$ of the total variance) were significantly correlated with temperature and/or precipitation. Furthermore, with respect to the tree-ring chronology loadings on the PCs, only fir at lower elevation sites displayed a relatively larger value $(0.933)$, with the other species at various sites having values below 0.15 . The basic correlation between PCs and annual climate variations does enhance the possibility of predicting radial growth trends of species along an altitudinal gradient at Changbai Mountain.

Based on the linear models of PCs derived from temperature and precipitation, and the PC loadings of each tree species, and assuming that current trends and ranges of annual average, mean maximum, and mean minimum temperature will continue in the future in the context of a warming climate, this study considered how radial growth of tree species at sites along an altitudinal gradient on Changbai Mountain might respond under scenarios in which the temperature rises $2^{\circ} \mathrm{C}$ or $4^{\circ} \mathrm{C}$, and precipitation increases or decreases by 30\% (Table 2). Results showed that the radial growth of Korean pine on all three altitudinal sites on which it was measured, as well as that of Manchurian Ash on site 1, would increase; and that the amount of increase becomes larger as elevation and/or precipitation increase. For spruce, radial growth increases occur only at the site located at the upper elevational limit for that species; while larch and Erman's birch at the tree line would display the greatest increases in radial growth of all species.

\section{Discussion}

4.1 Site-specific species chronologies characteristics in response to climate

The altitude of sites on Changbai Mountain strongly influenced tree radial growth and the sensitivity of tree chronologies. The average ring width of all cores involved in this study (generally two cores were extracted from each tree) was $1.85 \mathrm{~mm}$ at $750 \mathrm{masl}$, and 0.60 at $2,000 \mathrm{~m}$, with a linear decrease of $1 \mathrm{~mm}$ per $1,000 \mathrm{~m}$ of ascending elevation (Fig. 3a). In this study, if tree growth trends were predicted exclusively by elevation (for Changbai Mountain, a $1,000 \mathrm{~m}$ increase in elevation would be equated to a 
Fig. 7 Correlations of the first six principal component score time series (PC1-PC6) with monthly climate variables. Dashed lines indicate significant correlations at $p<0.05$ and $p<$ 0.01 , respectively

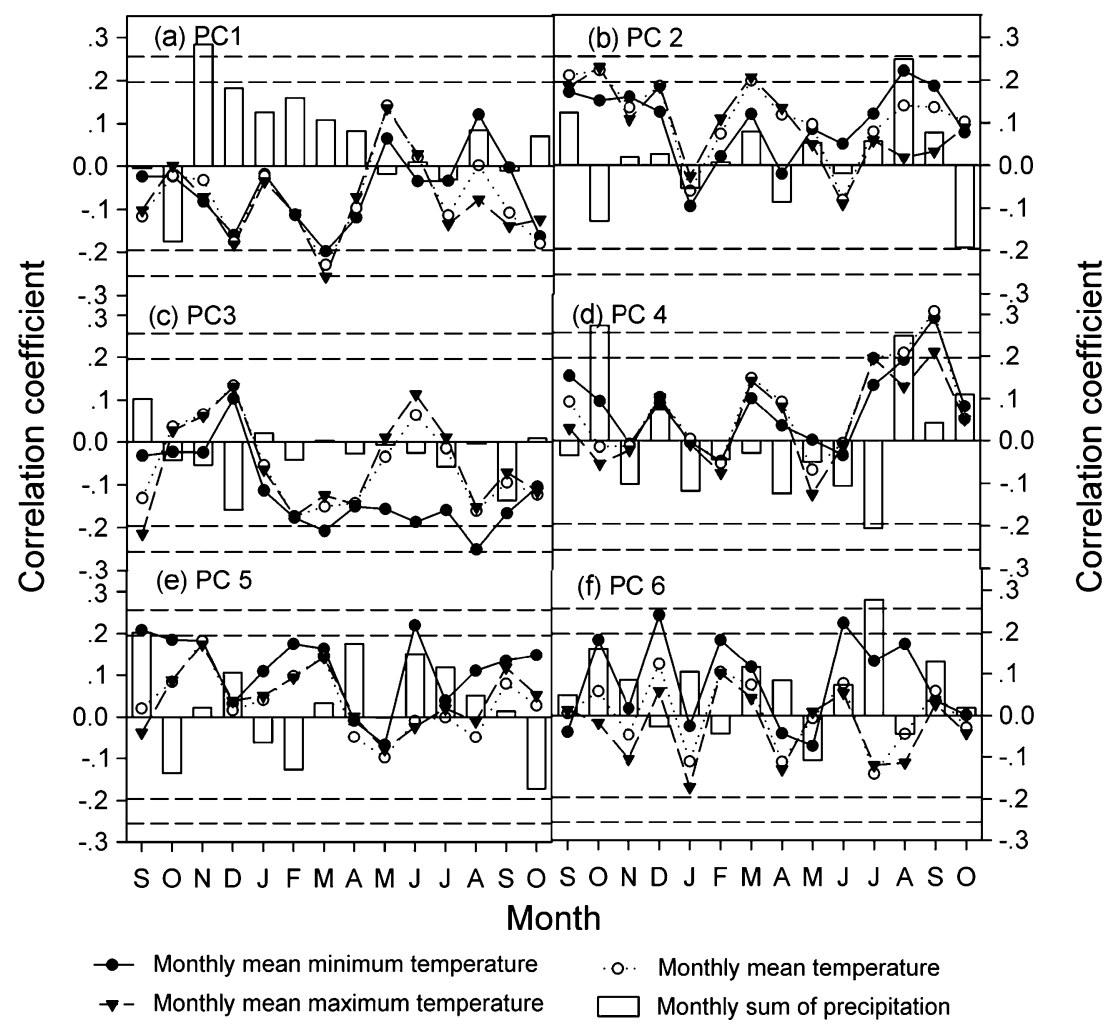

$2.8^{\circ} \mathrm{C}$ temperature increase (Yue et al. 2005)), a temperature increase of $2{ }^{\circ} \mathrm{C}$ would increase ring width by $50 \%$.

The sensitivity of almost all trees to climate intensified as altitude increased, and trees growing at higher altitudes or at their upper limit of distribution were more sensitive to climatic factors than were those at their lower limits. A notable exception to this was Korean pine (Fig. 3, Table 1). This may reflect the fact that density of conifer species increases with increasing elevation, which may in turn lead to more intense competition between Korean pine and other trees, as well as a relatively shorter period of exposure to open air in its life cycle. As a result, sensitivity to climatic factors may decrease. However, the mean interseries correlations (rabr) of all trees increased with ascending elevation (Fig. 3), which would suggest that the climate signal is stronger at higher altitudes.

For the entire altitudinal gradient, the greatest MS was displayed by Erman's birch at the tree line (2,000 masl), while Manchurian ash near the lower boundary of Changbai Mountain vegetation zones (750 masl) had the lowest MS. With respect to forest types on Changbai Mountain, in the Korean pine and broadleaved mixed forest (750-1,200 masl) the MS of Korean pine was the highest, making it the most suitable for dendrochronological study. In the spruce-fir forest (1,400-1,800 masl), spruces displayed the highest MS; while above 1,800 asl the only dominant tree species-Erman's birch — had the highest value for this measure.
4.2 General response of tree radial growth to climate

Despite abundant precipitation on Changbai Mountain, soil moisture still exerts a strong influence on tree radial growth, especially at the upper distribution limits of tree species. This can be inferred from correlations of tree-ring chronologies with PDSI (Fig. 7). Korean pine at all three sites, spruces at the three higher elevations sites, larch at the low elevation site, and Erman's birch at the tree line all displayed significant positive correlations with PDSI in the current growing season. Furthermore, spruces at the three higher elevations sites, larch at both lower and upper sites, and Erman's birch displayed positive significant correlations with annual PDSI (Fig. 8a), which was not consistent with an earlier report that the effects of precipitation decrease with increasing elevation (Wang et al. 2005). This study's finding that almost all of the tree-ring chronologies were positively and significantly correlated with precipitation in current-year August provided further evidence for the important role of soil moisture with respect to tree radial growth. The soil on Changbai Mountain was formed after volcanic eruptions, and its water-holding capacity is relatively low. High temperature (especially mean maximum temperature) in the growing season was associated with poor growth due to the depletion of soil moisture via high evapotranspiration rates.

PC1 highlighted the dominant influence of moisture availability on tree radial growth via its significant and 

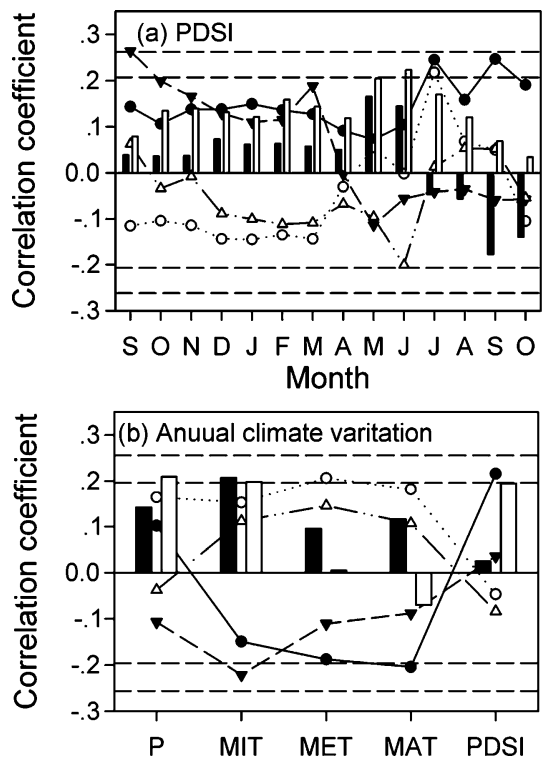

Annualization period climatic variables

P: annual total precipitation

MIT: annual average minimum temperature

MET: annual mean temperature

MAT: annual average maximum temperature

PDSI: annual average Palmer drought severity index

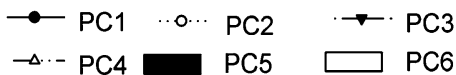

Fig. 8 Correlations of the first six principal component score time series (PC1-PC6) with: a monthly PDSI, and b annual average of monthly climate variables (October of previous year to current-year September) for the period of 1902-2000 (PDSI of 1912-2000). Dashed lines indicate significant correlations at $p<0.05$ and $p<0.01$, respectively

positive correlations with PDSI in the current growing season $(p<0.05$; Fig. $8 \mathrm{a})$ and annual PDSI $(p=0.037)$, and its negative correlation with annual average maxi- mum temperature ( $p=0.046$; Fig. $8 b)$. However, the strong relationship of winter precipitation and $\mathrm{PC} 1$ (Fig. 5a) may suggest that higher precipitation in association with warmer soil temperature in winter months is conducive to winter root survival and subsequently increased tree radial growth in the following year. Similarly, both this study and previous ones on Changbai Mountain found that winter precipitation positively affected radial growth of spruces at their upper distribution limit as well as Erman's birch at the tree line (Yu et al. 2006, 2007).

The effects of temperature on radial growth clearly differed for species at different sites along the elevational gradient. Correlations of tree ring chronologies with temperature were significant primarily in three time periods: late growing season of the previous year, and current-year spring (February-May) and growing season (June-August; Fig. 6). It should be noted that the temperature at the end of the growing season has a positive effect on tree radial growth, primarily for trees at lower elevations (below 1,400 masl), suggesting that warmer temperatures at the end of the growing season are helpful to accumulation of nutritious elements that subsequently benefit tree growth in the coming year (Zhu et al. 2009). At the same time, the effects of current spring and growing season temperatures on tree radial growth were complex and relative to sites and species. The results are further supported by the correlation between PCs and monthly climate variations (Fig. 5). These too revealed that the temperatures which limit tree growth on Changbai Mountain occur mainly in these three time periods. This is consistent with findings of previous research in the study area (Shao and Wu 1997; Zhang et al. 2007; Yu et al. 2006, 2007; Zhu et al. 2009).
Table 2 Tree radial growth trends under the climate change scenarios based on the linear relationships between radial growth, principal components time series and climatic variables

$\mathrm{T}+2 / \mathrm{T}+4$, temperature increase of $2 / 4^{\circ} \mathrm{C} ; \mathrm{P}+/-0.3$, precipitation increase/decrease of $30 \%$

\begin{tabular}{lcccccc}
\hline Site-species & $\mathrm{T}+2, \mathrm{P}+0.3$ & $\mathrm{~T}+2, \mathrm{P}+0.3$ & $\mathrm{~T}+2$ & $\mathrm{~T}+4$ & $\mathrm{~T}+2, \mathrm{P}-0.3$ & $\mathrm{~T}+4, \mathrm{P}-0.3$ \\
\hline PNK1 & 0.21 & 0.29 & 0.15 & 0.23 & 0.08 & 0.16 \\
PNK3 & 0.35 & 0.47 & 0.22 & 0.34 & 0.10 & 0.22 \\
PNK4 & 0.32 & 0.44 & 0.22 & 0.33 & 0.11 & 0.22 \\
FM1 & 0.12 & 0.17 & 0.09 & 0.14 & 0.06 & 0.10 \\
AN2 & 0.29 & 0.43 & 0.27 & 0.41 & 0.24 & 0.38 \\
AN4 & 0.06 & 0.08 & 0.03 & 0.05 & 0.00 & 0.02 \\
AN5 & 0.08 & 0.09 & 0.03 & 0.05 & -0.01 & 0.00 \\
PCK2 & 0.08 & 0.09 & 0.01 & 0.02 & -0.06 & -0.05 \\
PCK3 & -0.20 & -0.32 & -0.24 & -0.36 & -0.27 & -0.40 \\
PCK4 & -0.02 & -0.07 & -0.09 & -0.13 & -0.15 & -0.20 \\
PCK5 & -0.10 & -0.17 & -0.14 & -0.21 & -0.18 & -0.25 \\
PCK6 & 0.22 & 0.26 & 0.09 & 0.13 & -0.04 & 0.00 \\
LO3 & 0.05 & 0.06 & 0.01 & 0.02 & -0.03 & -0.02 \\
LO7 & 0.54 & 0.72 & 0.35 & 0.53 & 0.16 & 0.34 \\
BM7 & 0.77 & 1.01 & 0.46 & 0.70 & 0.15 & 0.40 \\
\hline
\end{tabular}


It is obvious that different tree species adapt to and require different ranges of climatic variables for maximum growth. At the upper altitudinal limit of species distribution, higher temperatures are beneficial to survival through cold winters (Liang et al. 2009). They also promote snowmelt and advanced growth prior to the growing season (Dang et al. 2007) and stimulate increased growth rates in the growing season (Frank and Esper 2005). At species' lower limits of distribution, the maximum temperature in the growing season has already approached the upper limit species can tolerate. Thus, warmer temperatures will only enhance stress and retard growth rates (Wang et al. 2005). However, our limited knowledge about ideal climate ranges for tree species and their specific site conditions increases the uncertainty regarding effects of climate variables on tree growth.

\subsection{Site-specific species growth in response to climate}

Our study suggests that the responses of tree radial growth to climate were influenced by both species and sites. This conclusion is supported by the results of the principal component loadings analysis (Fig. 4). However, the four groups into which all of the chronologies were divided based on loadings for $\mathrm{PC} 1$ and $\mathrm{PC} 2$, combined with the values of individual PC loadings, indicate that species differences were more influential than those of sites. This result mirrors that reported by Graumlich (1993), but differs from other findings in northwest China (Splechtna et al. 2000; Liang et al. 2010). As shown in Fig. 6, the main difference in radial growth response to climate occurred among the tree species of Korean pine, spruces, larch and Erman's birch, and such differences occurred primarily at upper and lower distribution areas of these species. It is possibly related to these site-specific responses to climate that the patterns of radial growth differ for the same tree species at different sites and for different tree species at the same site.

Previous models have found that climate warming will push the distribution area of Korean pine toward higher elevations, while at its lower limit of distribution growth will decline, perhaps even causing the species to disappear in current communities at this altitudinal level (Yan et al. 2000; Shao et al. 2003; Cheng and Yan 2008). At the same time, growth of broad-leaved tree species is projected to increase, causing them to occupy a greater proportion of area in the Korean pine and BP (Shao 1996; Shao et al. 2003). This study revealed that all Korean pine radial growth in the elevation range from 750 to 1,400 masl will increase with climate warming. This might be because the lower distribution limit of Korean pine is at an elevation of 500 masl, while the lowest sample site in our study is situated near the lower boundary of Changbai Mountain
Reserve Area at $750 \mathrm{~m}$. asl. However, the dominant broadleaved tree species in BP-Manchurian ash-displayed a smaller increase in rate of growth than did Korean pine, which might suggest that in BP the proportions of Korean pine and Manchurian ash will both increase, but that in terms of the increment, that of the former will exceed the latter. In this case, the results of this study did not support those reported by earlier models (Yan et al. 2000; Shao et al. 2003).

Spruces at all four lower sites-PCK2, PCK3, PCK4, and PCK5 - displayed decreasing growth with increased temperature regardless of any changes in precipitation levels. The significant correlation of spruces and precipitation reported by the tree-ring researchers in other areas may indicate that spruce is water-loving tree species (e.g., Peng et al. 2007). Results of this study suggest that while soil moisture is indeed a critical factor with respect to spruce radial growth, even a $30 \%$ increase in precipitation would not be enough to offset the water loss triggered by climate warming.

At the tree line, results from this study are similar to those from earlier models (Hao et al. 2001). Growth rates for larch and Erman's birch will increase by large percentages, and the dominance of the latter in tree line forests will be further enhanced.

\section{Conclusion}

In this dendroecological analysis designed to assess tree radial growth in response to climate on 15 sites along an altitudinal gradient on Changbai Mountain, species differences seemed to exert a stronger influence on growth responses than did site location (altitude). While precipitation is abundant in the area, it is the combined effects of precipitation, temperature, and soil moisture that constitute limiting factors to tree radial growth.

According to the principal components analysis and component responses to climate variations, the 15 sitespecific species chronologies may be divided into four groups. Species of spruce growth in the spruce-fir forest (above 1,200 masl) are most strongly affected by soil moisture and negatively correlated with annual maximum temperature; while spruce at and below 1,200 masl, are negatively correlated with annual minimum temperature. Korean pine growing above the Korean pine and broadleaved mixed forest (i.e., above 1,200 masl) are most strongly and positively influenced by annual average and maximum temperature. Larch and Erman's birch at the tree line (2,000 masl) and Manchurian ash in the Korean pine and broad-leaved mixed forest are positively affected by annual minimum temperature and precipitation; and the other species are mainly affected by temperature in late 
growing season of the previous year, as well as current late spring temperature and precipitation in the current growing season.

On an overall basis, the tree-ring network has provided some important information about interactions between forest growth and climate-related environmental influences and may be useful for the objective bioclimatic classification of forest populations. The results presented here could also be helpful in constructing simulation models of forest ecosystem responses to current and future climatic variability.

Acknowledgments This project was funded by the National Natural Science Foundation of China (No. 41071036 \&30800139), and the International Partnership Program for Innovation Team and the Visiting Professorship Program for Senior International Scientists of the Chinese Academy of Sciences.

\section{References}

Andreassen K, Slberg S, Tveito OE, Lystad SL (2006) Regional differences in climatic responses of Norway spruce (Picea abies L. Karst.) growth in Norway. For Ecol Manag 222:211-221

Briffa KR, Jones PD (1990) Basic chronology statistics and assessment. In: Cook ER, Kairiukstic LA (eds) Methods of dendrochronology. Kulwer Academic Publishers, Boston, Massachusetts, pp 137-152

Cheng XX, Yan XD (2008) Effects of climate change on typical forest in the northeast of China. Acta Ecol Sin 28:534-543, in Chinese with English abastract

Cook ER (1985) A time-series approach to tree-ring standardization. $\mathrm{PhD}$. thesis, University of Arezona: Tucson, Arizona

Cook ER, Glitzenstein JS, Krusic PJ, Harcombe PA (2001) Identifying functional groups of trees in west Gulf Coast forests (USA): a tree-ring approach. Ecol Appl 11:883-903

Dai AG, Trenberth KE, Qian T (2004) A global dataset of Palmer drought severity index for 1870-2002: relationship with soil moisture and effects of surface warming. J Hydrometeorol 5:1117-1130

Dang HS, Jiang MX, Zhang QF, Zhang YJ (2007) Growth responses of subalpine fir (Abies fargesii) to climate variability in the Qinling Mountain, China. For Ecol Manag 240:143-150

Frank D, Esper J (2005) Characterization and climate response patterns of a high-elevation, multi-species tree-ring network in the European Alps. Dendrochronologia 22:107-121

Fritts HC (1976) Tree rings and climate. Academic, New York

Graumilch LJ (1993) Response of tree growth to climatic cariation in the mixed conifer and deciduous forests of the upper Great Lakes region. Can J Fro Res 23:133-143

Hao ZQ, Dai LM, He HS, Malandnoff DJ, Shao GF (2001) Potential response of major tree species to climate warming in Changbai Mountain, northeast China. Chin J Appl Ecol 12:653-658, in Chinese, with English abstract

He HS, Hao ZQ, Mladenoff DJ, Shao GF, Hu YM, Chang Y (2005) Simulating forest ecosystem response to climate warming incorporating spatial effects in north-eastern China. J Biogeogr 32:2043-2056

Liang EY, Shao XM, Eckstein D, Huang L, Liu XH (2006) Topography- and species-dependent growth responses of Sabina przewaiskii and Picea crassifolia to climate on the northeast Tibetan Plateau. For Ecol Manag 236:268-277
Liang EY, Shao XM, Xu Y (2009) Tree-ring evidence of recent abnormal warming on the southeast Tibetan Plateau. Theor Appl Climatol 98:9-18

Liang EY, Shao XM, Eckstein D, Liu XH (2010) Spatial variability of tree growth along a latitudinal transect in the Qilian Mountains, northeastern Tibetan Plateau. Can J Fro Res 40:200-211

Liu Y, Bao G, Song HM, Cai QF, Sun JY (2009) Precipitation reconstruction from Hailar pine (Pinus sylvestris var. mongolica) tree rings in the Hailar region, Inner Mongolia, China back to 1865 AD. Palaeogeogr Palaeoclimatol Palaeoecol 282:81-87

Mitchell T, Jones PD (2005) An improved method of constructing a database of monthly climate observations and associated highresolution grids. Int J Climatol 25:693-712

Peng JF, Gou XH, Liu PX, Zhang Y, Fang KY (2007) Characteristics of ring-width chronologies of Picea crassifolia and their responses to climate at different elevations in the Anyemaqen Mountains. Acta Ecol Sin 27:3268-3276

Peterson DW, Peterson DL (2001) Mountain hemlock growth responds to climatic variability at annual and decadal time scales. Ecology 82:3330-3345

Shao GF (1996) Potential impacts of climate change on a mixed broadleaved-Korean pine forest stand: a gap model approach. Clim Change 34:263-268

Shao XM, Wu XD (1997) Reconstruction of climate change on Changbai Mountain, Northeast China using tree-ring data. Quaternary Sciences 3:76-85 (in Chinese with English abstract)

Shao GF, Zhao G (1998) Protecting versus harvesting of old-growth forests on the Changbai Mountain (China and North Korea): a remote sensing application. Nat Areas J 18:334-341

Shao GF, Yan XD, Bugmann H (2003) Sensitivities of species compositions of the mixed forest in eastern Eurasian continent to climate change. Glob Planet Chang 37:307-313

Splechtna BE, Dobrys J, Klinka K (2000) Tree-ring characteristics of subalpine fir (Abies lasiocarpa (Hook.) Nutt.) in relation to elevation and climatic fluctuations. Ann For Sci 57:89-100

Tardif J, Camarero JJ, Ribas M, Gutierrez E (2003) Spatiotemporal variability in radial growth of trees in the Central Pyrenees: climatic and site influences. Ecol Monogr 73:241-257

Wang Z, Xu ZB, Li X (1980) The main forest types and their features of community structure in northern slope of Changbai Mountain. Res For Ecosyst 1:25-32

Wang T, Ren HB, Ma KP (2005) Climatic signals in tree ring of Picea schrenkiana along an altitudinal gradient in the central Tianshan Mountains, northwestern China. Trees-Struct Funct 19:736-742

Xu DY, Yan H (2001) A study of the impacts of climate change on the geographic distribution of Pinus koraiensis in China. Environ Int 27:201-205

Yan XD, Zhao SD, Yu ZY (2000) Modeling growth and succession of northeastern China forests and its applications in global changes studies. Acta Phytoecol Sin 24:1-8 (in Chinese with English abstract)

Yu D, Tang L, Wang S, Wang S, Dai L (2004) Quantitative methodologies for ecotone determination on north slope of Changbai Mountains. Chin J Appl Ecol 15:1760-1764 (in Chinese with English abstract)

Yu D, Wang S, Tang L, Dai L, Wang Q, Wang S (2005) Relationship between tree-ring chronology of Larix olgensis in Changbai Mountains and the climate change. Chin J Appl Ecol 16:14-20 (in Chinese with English abstract)

Yu D, Wang Q, Wang GG, Dai L (2006) Dendroclimatic response of Picea jezoensis along an altitudinal gradient in Changbai Mountains. Sci China Ser E 49:150-159

Yu D, Wang GG, Dai L, Wang Q (2007) Dendroclimatic analysis of Betula ermanii forests at their upper limit of distribution in Changbai Mountain, Northeast China. For Ecol Manag 240:105-113 
Yue TX, Fan ZM, Liu JY (2005) Changes of major terrestrial ecosystems in China since 1960. Glob Planet Chang 48:287302

Zhang HS, Han SJ, Li YW, Zhang JH (2007) Reconstruction of temporal variations of precipitation in Changbai Mountains area over past 240 years by using tree-ring width data. Chin J Ecol 26:1924-1929 (in Chinese with English abstract)
Zhao SD, Yan XD, Yang SH, Tao DL, Dai LM (1998) Simulating responses of Northeastern China forests to potential climate change. J For Res 9:166-172

Zhu HF, Fang XQ, Shao XM, Yin ZY (2009) Tree ring-based February-April temperature reconstruction for Changbai Mountain in Northeast China and its implication for East Asian winter monsoon. Clim Past 5:1-6 